\title{
Innovaciones jurídicas, oportunidades políticas y cambios en la Policía de la Capital: el proceso de reforma del Código Procesal Penal en Córdoba (Argentina) en la década de 1930
}

Legal innovations, political opportunities and changes in the Police of the Capital City: the reform process of the Criminal Procedure Code in Córdoba (Argentina) in the 1930's

Innovations juridiques, opportunités politiques et changements dans la police de la Capitale : le processus de réforme du Code de Procédure Pénale à Cordoba (Argentine) dans les années 1930.

\section{Milena Luciano}

\section{OpenEdition}

\section{Journals}

Edición electrónica

URL: http://journals.openedition.org/rhj/1749

DOI: $10.4000 /$ rhj. 1749

ISSN: 0719-4153

Editor

ACTO Editores Ltda

\section{Referencia electrónica}

Milena Luciano, «Innovaciones jurídicas, oportunidades políticas y cambios en la Policía de la Capital: el proceso de reforma del Código Procesal Penal en Córdoba (Argentina) en la década de 1930 », Revista Historia y Justicia [En línea], 12 | 2019, Publicado el 29 mayo 2019, consultado el 05 julio 2019. URL : http://journals.openedition.org/rhj/1749 ; DOI : 10.4000/rhj.1749

Este documento fue generado automáticamente el 5 julio 2019.

Revista Historia y Justicia 


\section{Innovaciones jurídicas,} oportunidades políticas y cambios en la Policía de la Capital: el proceso de reforma del Código Procesal Penal en Córdoba (Argentina) en la década de 1930

Legal innovations, political opportunities and changes in the Police of the Capital City: the reform process of the Criminal Procedure Code in Córdoba (Argentina) in the 1930's

Innovations juridiques, opportunités politiques et changements dans la police de la Capitale : le processus de réforme du Code de Procédure Pénale à Cordoba (Argentine) dans les années 1930.

Milena Luciano

\section{NOTA DEL EDITOR}

Recibido: 21 de enero de 2019 / Aceptado: 05 de mayo de 2019

\section{Introducción}

Durante cuarenta años se sucedieron una serie de proyectos tendientes a reformar el Código Procesal Penal (en adelante, CPP) de la provincia argentina de Córdoba. Muchos juristas fueron convocados para la redacción de las distintas propuestas que, más allá de 
los consensos que lograban en el ámbito académico, se vieron obstaculizadas en el tratamiento legislativo.

El cambio legal recién tuvo lugar en 1939, durante el gobierno de Amadeo Sabattini (1936-1940), en una década caracterizada por el debilitamiento y fragmentación del sistema de partidos, con una progresiva intervención de la corporación militar en la vida política. Durante el radicalismo dicha intervención estuvo centrada principalmente en los conflictos laborales y en las intervenciones federales a las provincias. En efecto, el expresidente Hipólito Yrigoyen habría recurrido a tropas federales para ejercer el control de los procesos electorales en determinadas provincias, en donde la presencia del partido era débil ${ }^{1}$. Durante los gobiernos conservadores, la búsqueda de centralización política, en detrimento de las autonomías provinciales, se profundizó, posicionándose el radicalismo como representante de una democracia liberal permanentemente cuestionada por los conservadores, algunos de ellos en ocasiones muy cercanos a las ideas nacionalistas en auge luego de la Primera Guerra Mundial ${ }^{2}$.

3 Pero las tensiones con respecto al gobierno sabattinista no solo eran políticas partidarias, sino también involucraban la participación de burocracias penales, como lo era la justicia y la policía de la provincia. Esta última institución, siguiendo las directivas de Agustín P. Justo, habría realizado un seguimiento constante sobre A. Sabattini ${ }^{3}$, convertido en un referente del radicalismo yrigoyenista a nivel nacional durante la década del treinta.

Previamente se estaban produciendo cambios en la educación legal, un subsector específico del campo jurídico nacional, principalmente en la Universidad Nacional de Córdoba (en adelante, UNC) y, más tarde, en la Universidad de Buenos Aires (en adelante, UBA), como consecuencia de la recepción del Derecho Comparado alemán y francés. Dicho método de análisis doctrinario fue difundido por especialistas extranjeros contactados por profesores locales, entre ellos los doctores Sebastián Soler y Alfredo Vélez Mariconde, encargados de redactar el CPP de 1939.

5 Atendiendo a las trasformaciones ocurridas en el ámbito político nacional y provincial y a los cambios que tuvieron lugar en los estudios universitarios en la Facultad de Derecho de la UNC intentamos realizar un análisis que articule los procesos que sucedieron de manera contemporánea con el tratamiento legislativo del CPP de 1939, interrogándonos sobre las particularidades del contexto que posibilitaron su sanción.

6 Tanto la configuración de las instituciones penales como la historia política del siglo XX han sido estudiadas por la historiografía argentina de manera separada, evidenciándose cambios en los últimos años que propenden a establecer diálogos multidimensionales ${ }^{4}$. Sobre las transformaciones en la burocracia policial en Córdoba ${ }^{5}$, los nuevos enfoques recuperan la dimensión política que tuvieron dichos procesos, los cuales afectaron a la policía en su etapa formativa. Así pues, los cambios en la organización, reglamentos y capacitación de los funcionarios policiales son examinados teniendo en cuenta especialmente los reordenamientos burocráticos ${ }^{6}$. En cuanto a los estudios sobre los cambios en el Poder Judicial, los mismos son examinados principalmente desde una historia de las ideas jurídicas, atenta a los aspectos normativos. En esa dirección, la sanción del CPP de 1939 ha sido abordada a partir de sus bases y principios ${ }^{7}$, o bien relacionando la innovación normativa con la propuesta de gobierno sabattinista ${ }^{8}$. Aquí proponemos vincular el contexto político en donde se insertó la reforma y las estrategias desplegadas por los actores para el control de determinadas instituciones penales, como es el caso de la policía. 
7 En el presente trabajo nos interrogamos sobre las formas de relación que se establecieron entre los conocimientos producidos en el campo jurídico y su proyección hacia otras esferas, puntualmente en el campo político institucional y en la burocracia policial de Córdoba. Para ello, nos proponemos analizar, desde distintas perspectivas, el rol de los expertos en los procesos de recepción y circulación de los saberes que se erigieron como base teórica del CPP. Luego examinaremos el contexto político y social en el que se circunscribieron las discusiones, abocándonos al grado de autonomía estatal ${ }^{9}$ en la definición de los lineamientos penales con efectos en la Policía de Córdoba. En este apartado nos detendremos en un caso policial como lo fue la desaparición de Marta Stutz, en noviembre de 1938. A este hecho lo consideramos relevante, no solo por la resonancia mediática que tuvo a nivel nacional ${ }^{10}$, sino por sus implicancias en la organización de la Policía de la Capital y en la gestión sabattinista. Por último, abordaremos la construcción de consensos en la esfera institucional sobre la necesidad de una reforma procesal penal y las tensiones entre los actores encargados de materializar la misma.

\section{Saberes penales y disputas epistemológicas en el campo jurídico provincial}

\subsection{El Derecho Penal en la Universidad Nacional de Córdoba y el Instituto de Derecho Comparado}

8 Los cambios en la enseñanza del Derecho Penal en la Facultad de Derecho de la UNC acontecieron con la creación y difusión-recepción internacional del Derecho Comparado como método de análisis doctrinario. Entre sus principales objetivos se encontraban elaborar ordenamientos jurídicos nacionales a partir del examen de otros cuerpos normativos foráneos, enriquecer la interpretación del Derecho nacional y fomentar procesos de convergencia en donde plantear un fondo común entre las legislaciones ${ }^{11}$.

a constitución de un campo de estudios de dimensiones trasnacionales estuvo encabezada, a comienzos del siglo XX, por juristas de Francia, Alemania e Italia. En Argentina, las primeras traducciones de la dogmática jurídica alemana fueron realizadas por el jurista español Luis Jiménez de Asúa, intelectual que comenzó a establecer vínculos con referentes de las universidades nacionales a partir de la década de $1920^{12}$. En la UBA discutió con Norberto Piñero y Juan P. Ramos - profesores de la cátedra de Derecho Penalla necesidad de un nuevo método de enseñanza, superador de ciertas deducciones apriorísticas que el positivismo contemplaba. No obstante, en esa casa de estudios siguió teniendo una gran presencia la mencionada penología ${ }^{13}$.

10 En 1923, Jiménez de Asúa inició un ciclo de visitas a la Facultad de Derecho de la UNC, invitado por el profesor de Derecho Penal, Julio Rodríguez de la Torre y, posteriormente, por Sebastián Soler y Pablo Mariconde, docentes de la misma cátedra. Entre 1925 y 1930, el académico español dictó una serie de conferencias y cursos, los últimos de ellos sobre Criminología y Clínica y Derecho del Delito Político ${ }^{14}$.

11 Al igual que en la UBA, la impronta del positivismo criminológico estaba muy presente en los planes de enseñanza de la Facultad de Derecho de la UNC ${ }^{15}$; sin embargo, la transición epistemológica hacia la dogmática jurídica alemana se habría producido con anterioridad. En términos generales, la escuela penal positivista consideraba al delito como un "hecho social”, lo que implicaba una reconstrucción de la noción de responsabilidad jurídica 
focalizada en el sujeto que cometía un delito, postulando la existencia de condiciones biológicas, psicológicas o sociales que lo afectaban y lo inducían a delinquir ${ }^{16}$ ("peligrosidad pre-delictual"), noción que en el ámbito académico local fue reformulada por intelectuales positivistas que se desempeñaron en la cátedra de Derecho Penal, como el jurista Cornelio Moyano Gacitúa, para quien el delincuente era ante todo un individuo que realizaba sus acciones de manera libre y racional ${ }^{17}$ y que, por ende, era responsable de sus actos delictivos.

En tanto, la dogmática jurídica penal tiene como base de sus proposiciones "científicas" (sujetas a verificación) la interpretación del contenido del Derecho Positivo vigente y su sistematización ${ }^{18}$, elaborando sistemas de normas que pudiesen aplicarse de manera universal. La teoría del delito ${ }^{19}$ contemplada por la dogmática jurídica penal, considera que el mismo se compone por distintos elementos que funcionan como presupuestos necesarios para su configuración, de manera sistemática y sucesiva. El primer elemento necesario del delito es la acción, la cual será injusta e ilegal en función del segundo elemento, a saber, la tipicidad, característica que adecúa la acción a un tipo penal de trasgresión de la norma. Muy relacionado con lo anterior, el tercer elemento es la antijuridicidad, que denota la contradicción con el Derecho. Por último, resta establecer la culpabilidad del autor/a, es decir, si es plenamente capaz y consciente de sus actos y de la antijuridicidad de su conducta ${ }^{20}$.

13 Si bien encontramos la influencia del Derecho Comparado alemán, la presencia de la corriente francesa también cobró gran relevancia en Córdoba, principalmente en la proyección del Instituto de Derecho Comparado (en adelante, IDC), propuesto por el decano de la Facultad de Derecho de la UNC, Jorge Núñez y presidido por el jurista Enrique Martínez $\mathrm{Paz}^{21}$ en 1939. Esta institución habría sido muy importante para institucionalizar los intercambios académicos con otros países, tanto europeos como americanos, en donde la difusión del Derecho Comparado se encontraba en auge.

En este sentido, el jurista francés Edouard Lambert, creador del Instituto de Derecho Comparado de Lyon, a través de Alberto Justo -uno de sus integrantes-, planteó al decano argentino la necesidad de establecer vinculaciones más estrechas para la formación de una conciencia jurídica interamericana. Según lo expresado por el académico, el establecimiento de instituciones de ese carácter en Argentina favorecería la articulación de contactos latinoamericanos, pero fundamentalmente con Estados Unidos, país que hasta ese momento había sostenido una política aislacionista. Así, mediante el Colegio de Abogados de Estados Unidos y el Instituto de Derecho Americano ${ }^{22}$ se buscaría complementar la información ya recabada en otros institutos latinoamericanos, frente a un contexto europeo signado por la amenaza de una anarquía jurídica internacional ${ }^{23}$.

Otras dos influencias extranjeras que recibió el mundo jurídico cordobés, y que denotarían la formación progresiva de una red de especialistas locales y extranjeros, fueron Roberto Goldschmidt y Marcelo Finzi. Ambos juristas se integraron a las actividades del IDC contribuyendo en la traducción de obras de Derecho, el dictado de cursos y la conformación de acervos documentales y bibliográficos ${ }^{24}$. Los aportes de Roberto Goldschmidt, intelectual alemán perseguido por el nazismo y exiliado en Córdoba durante poco más de una década -entre 1939 y 1952-, se basaron en la traducción y enseñanza del Derecho Penal Administrativo alemán. El académico consideraba que las dificultades que presentaban las contravenciones, en cuanto al régimen aplicable, podían resolverse a través del Derecho Administrativo, y no necesariamente mediante el Derecho Criminal ${ }^{25}$. Por su parte, Marcelo Finzi, víctima de las políticas antisemitas implementadas 
en Italia por Benito Mussolini desde 1938, logró radicarse en la provincia mediterránea luego de una serie de inconvenientes que demandaron la intervención de Amadeo Sabattini y de Sebastián Soler, a los fines de efectivizar su ingreso al país ${ }^{26}$.

La trayectoria académica de Marcelo Finzi estuvo orientada a la investigación criminal aplicada a la institución policial. Se desempeñó como secretario del IDC llevando a cabo la traducción de obras extranjeras, entre las más importantes destacó el Código Penal alemán, tarea que realizó en conjunto con el intelectual local Ricardo Núñez ${ }^{27}$. Al igual que A. Justo, el penalista italiano visitó Estados Unidos entre marzo y abril de 1941, en calidad de representante del IDC, invitado por la Graduate Faculty of Political and Social Science, con el objeto de estudiar la organización de institutos y centros académicos similares a la institución académica cordobesa ${ }^{28}$.

En el IDC también encontramos a Sebastián Soler y Alfredo Vélez Mariconde, autores del Código Procesal Penal de 1939. Soler, hijo de inmigrantes españoles y partícipe de la Reforma Universitaria de 1918, se posicionó de manera crítica frente a los métodos de enseñanza tradicionales que caracterizaban a las cátedras de la UNC por esos años, por lo que propuso una reforma pedagógica, así como un acercamiento de los saberes que se discutían en el ámbito académico a las necesidades de la sociedad en general ${ }^{29}$. El intelectual comenzó a criticar los postulados positivistas en diferentes publicaciones ${ }^{30}$, que datan de la década de 1920, incorporándose al Instituto a cargo de la sección Derecho Penal. Paralelamente se desempeñó en la esfera penal cordobesa, como secretario del Juzgado en lo Criminal de Instrucción y Sentencia de $2^{\mathrm{a}}$ Nominación de Córdoba y como director de la Penitenciaria San Martin, entre 1932 y $1936^{31}$.

Por su parte, Alfredo Vélez Mariconde ejerció en la justicia provincial como escribiente, secretario y juez del Juzgado del Crimen n³, agente fiscal y vocal de la Cámara del Crimen $n^{\circ} 2^{32}$; mientras que en la Facultad de Derecho de la UNC se desempeñó como profesor de la cátedra de Organización Judicial y Procedimientos Penales, desde 1930. Además, formó parte de otras instituciones nacionales e internacionales, como el Instituto de Derecho Procesal de la Facultad de Derecho de la UBA (1949), la Sociedad Peruana de Ciencias Penales (1947), el Instituto Español de Derecho Procesal (1949), el Instituto Mexicano de Derecho Procesal (1960) y el Comité Permanente de Derecho y Procedimientos Penales del Colegio de Abogados de Estados Unidos $(1966)^{33}$. Como escritor de códigos, fue autor de los cuerpos normativos procesales para Santiago del Estero (1941), Mendoza (1952), Corrientes (1966) y nuevamente para Córdoba en $1968^{34}$.

19 Atentos a lo anterior, el clima de ideas en el campo jurídico de la Ciudad de Córdoba, específicamente en lo relativo al Derecho Público, Derecho Penal y Derecho del Procedimiento Penal, entre las décadas del veinte y cuarenta denotaba una circulación de saberes basada en la recepción de la Dogmática Jurídica alemana. La importación se manifestó mediante la presencia de expertos, ya sea a través de cursos dictados en este espacio, de la traducción de obras luego incorporadas al material de estudio del Derecho Penal en la UNC y de la construcción de redes por parte de los juristas cordobeses.

\subsection{El rol de los expertos en las innovaciones jurídicas: perspectivas de análisis}

Sobre los procesos de circulación de saberes nos interesa plantear a continuación distintas propuestas que intentan explicar su configuración y los objetivos que habrían 
impulsado a los expertos a establecer contactos trasnacionales respecto a determinadas temáticas y problemas.

La noción de red intelectual hace referencia a un conjunto de personas que producen y difunden conocimiento, manteniendo a lo largo de los años una comunicación constante, en función de intereses profesionales ${ }^{35}$. Los agentes culturales -en este caso el IDCestablecen y mantienen los intercambios, e introducen de esa manera nuevos paradigmas extranjeros en la academia local. En dicha actividad, los actores políticos muchas veces intervienen, por ejemplo, para facilitar el ingreso al país de los expertos (tal como hizo A. Sabattini con Marcelo Finzi), siendo la principal motivación de los intercambios nutrir los ordenamientos nacionales a partir de las discusiones con especialistas extranjeros. Esta mirada les otorgaría a los agentes políticos un rol secundario, puesto que la motivación principal de los intercambios estaría basada en el enriquecimiento del campo de estudios. Otros planteamientos analizan la movilización de saberes discutidos en el ámbito académico hacia la esfera política institucional, focalizándose en el rol activo de los expertos en la política pública. En este sentido, la construcción de consensos desde espacios vinculados con el saber, respecto a la necesidad de implementar reformas institucionales para solucionar determinados problemas, es definido como expertise. Dicho saber sería demandado socialmente por considerarlo de utilidad para resolver situaciones conflictivas $^{36}$. Los procesos de recepción se explican a través de la producción y circulación nacional e internacional de saberes y de personas, en donde lo expertos se constituyen como productores/exportadores, receptores/importadores, o bien como generadores/reproductores de saberes y discursos que luego se materializan en prácticas o dispositivos ${ }^{37}$. De esta manera, la incidencia de los juristas en el espacio universitario e institucional se orientaría al planteamiento y solución de problemáticas en el terreno de la política pública.

Sobre la dinámica de recepción centro-periferia, Máximo Langer propone dos modelos que invierten dicha relación: la difusión horizontal-semi horizontal desde la periferia (entre actores de países periféricos) y la difusión triangular desde la periferia (entre actores periféricos que persuaden a actores de países centrales para promocionar saberes en otros países periféricos) $)^{38}$.

Según Langer, las redes de intercambios entre expertos se inician a partir de la percepción de los activistas sobre una problemática particular. A partir de allí comenzarían a elaborar argumentos que legitimen posibles reformas, persuadiendo a las legislaturas nacionales sobre la necesidad del cambio. Según esta perspectiva, el apoyo político es fundamental para materializar los proyectos en el ámbito institucional ${ }^{39}$.

Siguiendo a Pierre Bourdieu, las prácticas y discursos jurídicos son producto -y se explican a partir- del funcionamiento del campo jurídico y su lógica determinada por las relaciones de fuerza existentes en su estructura, que, a su vez, orientan las luchas en función de la lógica interna de las acciones jurídicas que definen y limitan lo posible ${ }^{40}$. En esa dirección, cobran relevancia la procedencia y relaciones sociales que poseían Soler y Vélez Mariconde, y sus trayectorias académicas como estrategias para validar el acceso a las burocracias estatales.

Mientras Velez Mariconde, proveniente de una familia de la elite cordobesa que progresivamente ganaba posiciones en el ámbito académico, contaba con una serie de relaciones sociales dentro del mundo del Derecho; Soler, como hijo de inmigrantes españoles, carecía de relaciones sociales tradicionales que le permitiesen tener una 
posición dominante en el campo jurídico. En sus cargos de profesores de la Facultad de Derecho de la UNC comenzaron a cuestionar doctrinas legales muy arraigadas, como el positivismo criminológico, lo cual se traduciría en una inversión de capital jurídico teórico de los académicos recién llegados, intentando generar consensos sobre nuevas formas de analizar el derecho, incluyendo la dogmática germana con el objeto de mejorar sus posiciones dentro del campo jurídico ${ }^{41}$.

Sobre las posibles motivaciones e intereses de los agentes para promover ciertas reformas, Yves Dezalay y Bryant Garth sugieren la existencia de una estrategia internacional en la circulación de saberes de gobierno, enmarcada en un contexto de lucha hegemónica en donde es fundamental, en primera instancia, el apoyo gubernamental de los países centrales para exportar esos saberes y ensayar políticas en la periferia ${ }^{42}$. En ese momento cobran relevancia las luchas que se libran en la esfera política nacional a través de las negociaciones entre las elites locales y los expertos en torno a la recepción de saberes $^{43}$. En efecto, adquiere relevancia la configuración del contexto político nacional y provincial, en donde se enmarca el accionar de los agentes políticos gubernamentales convergente con las estrategias desplegadas por los juristas.

De los enfoques planteados nos interesa recuperar algunas herramientas de análisis que permitirán comprender el panorama político argentino y, en particular, la situación de Córdoba durante el proceso de reforma del CPP. Como ya se trató en párrafos anteriores, las categorías de red intelectual y expertise cobran relevancia para explicar lo acontecido en el ámbito académico en las primeras décadas del siglo XX. En el próximo apartado nos enfocaremos en el escenario político local que habría permitido que la importación de saberes fuese exitosa, analizando aquellos intereses políticos que valorizaron dichos capitales jurídicos, es decir, intentaremos incorporar a nuestro estudio las perspectivas que otorgan a los agentes políticos gubernamentales -locales e internacionales- un rol primordial en las innovaciones jurídicas. Haremos foco, por un lado, en la persecución política que afectó los miembros de la Unión Cívica Radical luego del Golpe de Estado de 1930 y, por el otro, desarrollaremos los conflictos generados por la politización de un caso policial sucedido en Córdoba durante el tratamiento del proyecto del CPP, el cual adquirió gran relevancia en la opinión pública, afectando a la Policía de la Capital y, en consecuencia, a la gestión sabattinista.

\section{Presiones y oportunidades: contexto político partidario y reformas en la Policía de la Capital}

Tras el Golpe de Estado que derrocó al presidente Hipólito Yrigoyen, la Unión Cívica Radical (en adelante, UCR) fue objeto de una constante persecución política, la cual aminoró el protagonismo electoral que había tenido en los últimos años, ya sea a través de su proscripción, o bien cuando resolvió recurrir a la abstención. La policía, encargada de brindar información sobre las actividades realizadas por la disidencia política, atravesó una importante reestructuración emprendida por los conservadores. Puntualmente, se produjo el control por parte de la corporación militar de las altas esferas de la jerarquía policial ${ }^{44}$, existiendo -según lo señalado por Laura Kalmanowiecki- colaboración de la policía provincial con las operaciones de inteligencia militar hasta $1933^{45}$.

Estas condiciones plantearon nuevas formas de participación política de la UCR, por fuera de la estructura partidaria-electoral, ya que, como sostiene Cesar Tcach, la abstención 
lejos de ser una medida de resistencia pasiva pretendía utilizar la violencia política como medio para deponer a los conservadores ${ }^{46}$. De esta forma, la estrategia armada caracterizó la participación política radical entre 1930-193347.

31 Amadeo Sabattini, junto con Donato Latella Frías, Humberto Cabral y otros radicales yrigoyenistas, fueron algunos de los partícipes de una serie de fallidos levantamientos en complicidad con suboficiales del ejército ${ }^{48}$. A. Sabattini fue detenido en 1933, luego de que la Policía de Córdoba encontrase armas y explosivos en la casa de Arturo Arnella, no obstante, quedó en libertad al poco tiempo ${ }^{49}$. Sobre los supuestos planes del levantamiento y la participación de miembros de las Fuerzas Armadas, policía y penitenciarios, el interventor de Córdoba, Carlos Ibargúren manifestaba lo siguiente:

"se instalaría en Córdoba, triunfante la conspiración, una junta revolucionaria y como primera medida habían planeado mi fusilamiento, el de mis ministros secretarios y demás altos funcionarios de la intervención. Consta igualmente en el sumario que los jefes y oficiales del Ejército leales al gobierno se les mataría en los cuarteles por la tropa amotinada (...) Los cabos y sargentos declararon que los dirigentes políticos de la asonada les habían prometido grandes beneficios, entre los que figuraban en primera línea acordarles, si triunfaban, facilidad para escalar los grados de oficial mediante algunos estudios en escuelas especiales (...) Con tales perspectivas sedujeron también al cuerpo de bomberos, al de guardia cárceles, al escuadrón de seguridad y a empleados policiales" ${ }^{50}$.

El papel de los interventores fue muy importante en el periodo de normalización institucional, pues los representantes de los partidos provinciales debieron acordar con ellos las condiciones para una nueva contienda electoral que designase a los próximos gobernantes. En efecto, el Partido Demócrata de Córdoba ${ }^{51}$ llevó adelante una serie de encuentros con Ibarguren para lograr ese cometido, ocurriendo en consecuencia una reorganización al interior del partido de cara a las elecciones de $1931^{52}$. En ese contexto fueron enviadas comisiones especiales desde el gobierno nacional hacia la provincia de Córdoba, para "modernizar la organización" de la Policía de la Capital a través de la creación de nuevas ramas abocadas a la clasificación y control de la disidencia política ${ }^{53}$.

Progresivamente, las limitaciones de la estrategia armada del radicalismo como medio para acceder al poder fueron dejando lugar a la vía electoral. En enero de 1935, el partido anunció el fin de la abstención ${ }^{54}$. Esto le permitió a Sabattini presentarse como candidato y ganar las elecciones para gobernador de Córdoba, erigiéndose como representante de la lucha por la autonomía provincial frente a las presiones políticas del régimen nacional que, a través de sucesivos informes elaborados por el ejército con colaboración de la policía local, denunciaban en Córdoba una situación de anarquía que demandaba su inminente intervención federal ${ }^{55}$. Sobre este asunto, el flamante mandatario electo acusaba a los conservadores de avanzar progresivamente sobre las facultades de las provincias para concretar sus aspiraciones centralistas, proponiendo como eje de su programa político el "afianzamiento de la autonomía en los límites y condiciones que la Constitución Nacional establece y en el cumplimiento de las leyes existentes"56. Una de las estrategias del radical cordobés consistió en la designación de militantes yrigoyenistas en la administración pública. Tal como señalaba en su memoria Carlos Ibarguren, luego de la reorganización llevada a cabo por la gestión de A. Sabattini en la Policía de Córdoba, muchos militares que participaron de los distintos levantamientos fueron ubicados en la repartición ${ }^{57}$.

Al mismo tiempo, la propuesta de gobierno sabattinista remarcaba el respeto y fortalecimiento del orden constitucional ${ }^{58}$ con una serie de reformas vinculadas con la 
elección de autoridades municipales, la profesionalización de la policía y respecto a los procedimientos criminales, civiles y comerciales. Medidas tendientes a la "modernización política y jurídica" de la provincia mediterránea ${ }^{59}$, pero también orientadas a "despolitizar" a la policía local, a través de reformas legales que garantizaren su control por parte del Poder Judicial.

Con relación al Código de Procedimientos Penales vigente en Córdoba desde 1889, Sabattini planteaba la necesidad de una reforma, entre otros motivos, por considerar que se trataba de una legislación basada en ordenamientos de la España monárquica, por lo cual debía modificarse de manera que respondiese a "las exigencias de una buena administración de justicia" ${ }^{60}$. Fue así como una de sus acciones en el gobierno consistió en decretar la redacción de un nuevo CPP a los doctores Ernesto Peña, Sebastián Soler y Alfredo Vélez Mariconde; renunciando el primero de ellos antes de comenzar la tarea, debido a su designación como diputado nacional ${ }^{61}$.

Sin embargo, proyectar reformas procesales en materia penal no era una novedad en la historia parlamentaria cordobesa, puesto que previamente fueron presentados cuatro proyectos $(1901,1918,1922$ y 1924) que no alcanzaron su sanción debido a diferentes factores, como disposiciones anacrónicas respecto a las reformas constitucionales provinciales como a las comprendidas en el Código de fondo. La segunda situación se produjo con la propuesta de reforma de 1918, elaborada por José Del Viso, Enrique Martínez Paz y Julio Rodríguez de la Torre, que tuvo tratamiento legislativo luego de que entrara en vigor el Código Penal de la Nación de $1922^{62}$.

Pero junto con los argumentos específicamente normativos, José D. Cesano explica las demoras en términos de coyunturas político-partidarias desfavorables ${ }^{63}$, considerando la incidencia de factores que podrían haber ejercido presión para obstaculizar el cambio normativo. Sobre el grado de autonomía que posee el Estado para orientar sus políticas penales recuperamos una de las dimensiones del Estado Penal ${ }^{64}$ analizadas por David Garland, a saber, la autonomía estatal. El autor interroga sobre el grado de influencia que poseen en los procesos de legislación penal de los Estados democráticos, por un lado, las demandas externas representadas por grupos de interés, opinión pública o iniciativas electorales; y por el otro, el peso de las ideologías e intereses de las burocracias estatales. En efecto, los funcionarios actuarían con mayor autonomía en la medida en que los lineamientos penales se correspondiesen principalmente con el asesoramiento de expertos $^{65} \mathrm{y}$, en un segundo plano, como respuesta ante las demandas de la sociedad en general.

En el momento en que A. Sabattini asumió el gobierno, las cámaras del Poder Legislativo de Córdoba estaban compuestas por 24 diputados radicales, frente a los 12 del Partido Demócrata de Córdoba; mientras que, entre los senadores, los demócratas eran mayoría, con 18 representantes frente a 11 de la UCR. El proyecto de reforma ingresó y se discutió, en primer lugar, en Senadores, en 1937, con una demora de un año y medio antes de ser discutido por una Comisión Bicameral en distintas reuniones en el plazo de dos meses y, finalmente sancionado en Diputados, el 22 de agosto de $1939^{66}$.

En pleno tratamiento del proyecto un hecho criminal generó tensiones políticas entre demócratas y radicales, poniendo en la mira a la Policía de la Capital. Puntualmente, nos referimos al caso de la desaparición de una niña de nueve años, a metros de su hogar y en cercanías de la Comisaría Novena, ubicada en el barrio San Martin de la ciudad de Córdoba. Dicho suceso pondría en evidencia una serie de negligencias de las que hacía varios años adolecía la policía local -principalmente en la etapa de instrucción-, aspecto 
que, como veremos, estaba contemplado en el proyecto de reforma de CPP delineado por Soler y Vélez Mariconde.

Según relató el diario cordobés La Voz del Interior del 19 de noviembre de 1938, Marta Stutz se habría dirigido desde su casa hacia un puesto de publicaciones para comprar la revista Billiken y nunca regresó67. En adelante, la División de Investigaciones de la Policía de Córdoba inició una búsqueda que barajó no solo múltiples posibilidades de configuración de delitos (secuestro, homicidio, tráfico de mujeres y niñas), sino también una serie de acusaciones basadas, muchas veces, en datos aportados por el público general. Un ejemplo del pedido de colaboración a la sociedad cordobesa fue la publicación realizada por La Voz del Interior el día 23 de noviembre de 1938, en donde manifestaba que el "dolor de los progenitores, la aflicción de la sociedad y, sobre todo y ante todo, la vida de esa inocente criatura, exigen a todos un amplio espíritu de colaboración y una solidaria cooperación para develar el misterio que se cierne sobre el secuestro"68.

Al respecto, Jaqueline Vasallo señala que la Policía de Córdoba por esos años no estaba preparada para investigar delitos complejos, por lo cual otro de los elementos que tuvo peso para detener a una gran variedad de sujetos fue la existencia de antecedentes penales ${ }^{69}$.

La hipótesis del secuestro movilizó la participación del Ejercito (Regimiento 13 de Infantería), poniendo en contacto a las policías de San Luis, La Pampa, Mendoza y Capital Federal. Provenientes de esta última repartición llegaron a la ciudad de Córdoba, a comienzos de diciembre, el comisario Finochietto y los empleados de policía Cazes, Rizzo y Barrera, especialistas en asuntos criminales ${ }^{70}$.

43 Tras un mes de intensa búsqueda se dio a conocer por el medio de prensa local la noticia de la aparición de restos óseos que corresponderían a un menor de aproximadamente diez años, situación que generó una gran conmoción en muchos ciudadanos, quienes se dirigieron a la Central de Policía, al Palacio de Justicia y a la casa de Deodoro Roca, abogado defensor de uno de los acusados ${ }^{71}$ del secuestro y muerte de Stutz, iniciando una serie de protestas que incluyeron ataques a los edificios mencionados. Según funcionarios de la Policía de la Capital, se trataba de "elementos fascistizantes y adversarios políticos del actual gobierno que parecieran haber querido aprovechar de la agitación pública para avivar la exaltación colectiva en contra del gobierno y de personas de posición más o menos definida en lo que se refiere a ideología"72.

Días después, la versión del hallazgo fue perdiendo veracidad, desplazándose el foco hacia la negligencia policial y la gestión sabattinista. Entre las irregularidades realizadas por la policía de Córdoba en la fase de instrucción se destacó la participación de videntes con el objeto de develar el paradero de la niña, la implantación de pruebas recolectadas por miembros de la fuerza para sostener la culpabilidad de Humberto Vidoni específicamente de cenizas que no correspondían a una niña, sino a un hombre adulto-, el uso de apremios ilegales en las declaraciones de los acusados, llegando al extremo de provocarle la muerte a Vidoni ${ }^{73}$.

Con respecto la situación de la policía, $L a$ Voz del Interior en una de sus editoriales señalaba las grandes carencias que afectaban a la repartición en cuanto a recursos humanos y técnicos, que obstaculizaron gravemente la investigación ${ }^{74}$. En consonancia con ello, días después las autoridades procedieron a revisar los antecedentes penales de los empleados de policía. Este procedimiento provocó la solicitud de licencia por parte del jefe de Policía, Argentino Auchter, designándose en su lugar y con carácter de interino al ingeniero José 
de la Peña. En su solicitud, Auchter explicitaba la existencia de actitudes oportunistas por parte de sectores de la oposición, que utilizaban el caso en función de sus disputas políticas:

"Un hecho criminal, que por su monstruosidad ha apasionado a la opinión pública, es explotado por espíritus pequeños en detrimento de la Repartición a mi cargo, dirigiendo contra mi persona una serie de falsas imputaciones.

Aunque esta campaña, por manifiestamente interesada e injusta, no puede rozar mi dignidad de hombre y de funcionario, puede en cambio lesionar los sanos prestigios de la institución policial que deben estar siempre por encima de toda sospecha"75. acusaba a los demócratas de utilizar políticamente la desaparición de Marta Stutz "para lograr su viejo sueño de intervención" presidido por Roberto Ortiz que, a diferencia de Sabattini, formaba parte del radicalismo antipersonalista ${ }^{81}$.

51 Finalmente, el jefe de Policía Argentino Autcher presentó su renuncia indeclinable al cargo, debido a las "expresiones injuriosas" pronunciadas por el diputado Juan Manubens Calvet, a quien no podía responder con el margen de libertad necesario por su rol de funcionario público y por los fueros que le otorgaba el parlamento al legislador demócrata ${ }^{82}$. Luego de múltiples hipótesis y acusaciones -y de cinco años de prisión preventiva- se resolvió absolver a Antonio Suárez Zavala, único sospechoso, por falta de pruebas, pues el cuerpo de Marta Stutz nunca apareció. 
52 En síntesis, podríamos decir que el contexto político partidario estaba signado por una serie de tensiones existentes a partir del Golpe de Estado de 1930 y profundizadas después del caso Stutz, debido a las posibilidades de intervención de la provincia de Córdoba, luego de que se hicieran públicas las irregularidades de la Policía. En este sentido, resulta de interés dimensionar si esta problemática intentó ser subsanada por el CPP, para ello a continuación examinaremos el contenido del nuevo cuerpo normativo en relación con una de las principales problemáticas: las deficiencias en la etapa de instrucción policial.

\section{Importadores/exportadores de saberes y luchas políticas locales: cambios en los procedimientos penales propuestos por la nueva normativa}

El Código de Procedimiento Penal de 1939, cuya redacción fue encargada por Amadeo Sabattini a los juristas Sebastián Soler y Alfredo Vélez Mariconde; contiene una serie de fuentes externas, tales como el Código Procesal Penal de Italia (1913 y 1930), la Ley de Enjuiciamiento Criminal de España (1882), la Ordenanza de Procedimientos Penales del Reich (1877) y el Código de Instrucción Criminal de Francia (1808) ${ }^{83}$. Ambos juristas combinaron la actividad académica que los dotaba de autoridad legal teórica y la creatividad de un legislador, debido a sus trayectorias en espacios institucionales y académicos. La posición de autor de código de procedimiento criminal les permitió constituirse, posteriormente, en referentes para la redacción de cuerpos normativos nacionales e internacionales ${ }^{84}$. Una de las potencialidades que se destacaron del proyecto de CPP de 1939, fue la capacidad de los juristas importadores de adaptar los conocimientos a la realidad local, esto es, considerar las posibilidades presupuestarias para poder responder, en el mediano plazo, a los requerimientos prescriptos y de consensuar con las elites políticas gobernantes la necesidad de una reforma.

Entre las innovaciones que planteó el CPP se encontraba la transición de un sistema inquisitivo hacia otro acusatorio. Esto significó que la facultad de acusar y de juzgar ya no recaería sobre la misma persona, distinguiéndose las funciones de investigación y juzgamiento. Los procesos penales comenzarían a ser orales y públicos, procurando otorgar mayores derechos al imputado ${ }^{85}$.

Según los juristas encargados de la redacción del proyecto de CPP de 1939, la oralidad en los procesos respetaría el principio de originalidad de la prueba al ser directamente recibida por el tribunal sentenciador, a diferencia de los procesos escritos en donde sucedía que los jueces analizaban pruebas recabadas por otros magistrados, "interpretando los documentos fríos de un expediente que quiere ser el espejo de la realidad y que consagra la derogación de la verdadera testimonial", obstaculizando así la reproducción lógica del hecho (búsqueda de la verdad real). Al mismo tiempo, esta concentración de la actividad procesal posibilitaría la celeridad de los juicios, la economización de la actividad jurisdiccional y su verdadera publicidad, respetando también el principio de contradicción, ya que permitiría la paridad jurídica a través de la libre discusión y el examen bilateral de todos los actos ${ }^{86}$.

56 Asimismo, los autores del nuevo Código plantearon la implementación de la instancia única. Entre los objetivos del cambio también se encontraba la mayor celeridad de los juicios, puesto que intervendrían en el juzgamiento tribunales colegiados, siendo cumplida la instrucción por un solo juez -a diferencia de la doble instancia, en donde los 
asuntos primero eran resueltos por un juez y luego revisados por una cámara integrada por un tribunal-, en cuanto a las cuestiones de hecho y de derecho, producción de pruebas y documentos realizada en primera instancia, por lo que no habría un doble proceso sino un doble juicio lógico (sentencia) ${ }^{87}$.

Durante el tratamiento del proyecto, el diputado demócrata David de la Torre Peña planteó como falencia de éste la inconstitucionalidad de la instancia única, puesto que en la Carta Magna Provincial solo se reservaba para una "determinada clase de juicios", siendo la regla general la doble instancia ${ }^{88}$. Desde el oficialismo, el diputado Hilario Martínez manifestó que ninguna disposición constitucional prohibía la instancia única, así como tampoco establecía expresamente las dos instancias de juicio ${ }^{89}$.

Entre los cambios propuestos por el proyecto de CPP de 1939 nos enfocaremos en lo relativo a la etapa de instrucción, la primera a realizarse previo al juicio. Dicha fase resulta fundamental y determinante en el proceso, pues se basa en la búsqueda de pruebas, producción y organización de éstas, tarea desarrollada por funcionarios policiales a cargo de la elaboración de sumarios que posteriormente formarán parte del expediente judicial ${ }^{90}$. Con respecto a los procedimientos que debía seguir esta etapa y los agentes encargados de la misma, el nuevo proyecto de Código propuso la creación de una Policía Judicial, abocada a la investigación de delitos, recolección de pruebas y descubrimiento e individualización de los culpables. En esta dirección se diferenciaba una policía administrativa, con funciones preventivas y una policía represiva compuesta por funcionarios judiciales, dirigida por el Fiscal de Cámara y bajo la autoridad del Tribunal Superior. Así, los autores del Código no solo proyectaron la nueva sección atentos al cumplimiento normativo de la etapa de instrucción, sino también insistieron en la necesidad de independencia e inamovilidad de los funcionarios de Policía Judicial frente a los cambios políticos; por ello, la designación y control del personal debía estar a cargo del Poder Judicial, a diferencia de la policía administrativa bajo la órbita del Poder Ejecutivo ${ }^{91}$.

59 La aprobación del proyecto se realizó con pocas modificaciones, pero de gran relevancia para el tema que nos ocupa. De los 588 artículos contenidos en el proyecto de CPP de Vélez Mariconde y Soler, fueron enmendados -aunque con modificaciones menoressesenta y cinco. Entre los aspectos que se vieron revisados se encontraba la suspensión provisoria del juzgamiento de faltas por parte de un juez correccional y de la creación de una Policía Judicial. La primera modificación se justificó, según José D. Cesano, en las limitaciones que afectarían a la policía en su función preventiva, orientada a la "eliminación de individuos indeseables", que deberían ser sometidos al procedimiento del expediente contravencional y a los tiempos que ello implicaba. Por lo cual, quedaba supeditada a la sanción de leyes posteriores que regulasen un código de faltas ${ }^{92}$.

60 Similar situación se produjo en cuanto a la suspensión de la Policía Judicial, puesto que, según lo manifestado por Juan Palmero -miembro informante del proyecto en la Cámara de Senadores-, su creación podría concretarse mediante Ley Orgánica de los Tribunales o por una ley especial (a través de un Departamento de Investigaciones dependiente del Tribunal Superior de Justicia) ${ }^{93}$. En efecto, los argumentos esgrimidos se basaron en cuestiones formales, a diferencia de lo sucedido, por ejemplo, en el tratamiento del proyecto de Código de Procedimiento Penal de la Provincia de Buenos Aires (1935) En este caso, la consulta de expertos para la discusión de aspectos vinculados con la organización de la justicia presentes en el proyecto de Eusebio Gómez y Rodolfo Moreno aconteció no 
solo en torno a cuestiones doctrinarias, sino también respecto a las posibilidades presupuestarias para su concreción ${ }^{94}$.

61 Sin embargo, la revisión de los aspectos que atañen a la tarea de instrucción policial en el proyecto de CPP no impidió la continuación y profundización de una serie de reformas en la Policía de la Capital, que ya se estaban produciendo con anterioridad. En efecto, los primeros cambios impulsados por A. Sabattini al asumir el cargo de gobernador de la Provincia apuntaron a su organización interna, sumándole a la ya creada División de Investigaciones tres secciones: División Central, División Judicial y División Administrativa ${ }^{95}$. Sobre su funcionamiento, concluido el año 1937, el jefe de Policía ${ }^{96}$ José Tristán Casas (1936-1938) manifestaba que la División de Investigaciones, si bien no contaba con el personal suficiente para desempeñarse eficazmente, había incorporado métodos modernos de fotografía y dactiloscopia e informaciones gráficas y técnicas tendientes a mejorar la recolección de pruebas ${ }^{97}$. Según el funcionario, la División Judicial habría optimizado la aplicación de castigos por faltas, perfeccionando la confección de sumarios policiales de manera completa y "lo más exactamente posible"98.

Después del caso Stutz, el plan de reformas continuó muy vinculado a las deficiencias e irregularidades que evidenció el hecho policial. Una de las medidas iniciales fue decretar la creación de la Escuela de Policía, en $1939^{99}$.

La organización de la escuela estuvo bajo la dirección de Francisco Laguarda ${ }^{100}$ siguiendo el modelo de la Policía de la Capital Federal, a los fines de formar y capacitar al personal de carrera perteneciente a la institución ${ }^{101}$. Tal como manifestaba Laguarda en una nota enviada al ministro de Gobierno Santiago del Castillo, la acción formadora de una escuela podría mejorar el accionar policial en la etapa de investigación criminal, logrando también de esa forma poner al cubierto a la repartición de "cargos y críticas exageradas o no, que de todos modos la perjudican"102.

En 1940, un referente de las innovaciones que se estaban produciendo en el ámbito académico local, Marcelo Finzi, fue contratado para desempeñarse como docente. El penalista italiano había sido profesor de las escuelas de policía científica de Ferrara, Bolonia y Roma en Italia, haciendo lo propio también en Lyon (Francia) y en Berlín (Alemania). Su formación en investigación criminal le valió la designación en la institución de Córdoba en donde dictó los siguientes cursos: "Precursores de la Policía Científica", "Curso de perfeccionamiento sobre la policía científica", "Una gloria argentina: Juan Vucetich" ${ }^{103}$. Como se observa en el siguiente fragmento, los principales contenidos de las conferencias dictadas por Finzi trataban aspectos relativos al sumario policial:

“a) Inspección ocular. Normas generales. Investigación relativa al cuerpo del delito. Rastro del delito. Instrumentos del delito. Planos descriptivos y fotográficos. Normas especiales en caso de hurto, de homicidio, de incendio doloso, de falsificación de moneda.

b) Reconstrucción del hecho bajo la dirección del Juez de instrucción.

c) Registro domiciliario. Donde y como se debe buscar. Expedientes para encontrar los objetos escondidos.

d) Requisa personal. Examen del cuerpo y de la vestimenta. Normas relativas.

e) Inspección personal y corporal. Importancia. Constataciones varias.

f) Secuestro. En particular, del secuestro de correspondencia.

g) Detención del culpable. Medios. Cautelas.

h) Interrogatorio del imputado. Concepto. Importancia. Valoración psicológica.

i) Examen de los testigos. Fundamento racional de la prueba testimonial. Valoración crítica de los testimonios. 
j) Reconocimientos. Concepto. Reconocimiento del imputado. Reconocimiento de objetos secuestrados.

k) Careo. Noción. Valoraciones psicológicas.

La exposición relativa a cada uno de los actos antedichos será precedida por breves nociones de derecho procesal" ${ }^{104}$.

Recuperando lo planteado al inicio del trabajo, consideramos que la construcción de consensos sobre la necesidad de una reforma en los planes de estudio del Derecho Penal habría comenzado en la década de 1920, consolidándose en el campo jurídico a través del Instituto de Derecho Comparado a comienzos de la década de 1940. Esta red de académicos cuestionó las tradiciones positivistas que predominaban en los planes de estudio del derecho penal en la UNC e introdujeron obras de la Dogmática Penal alemana que luego se incorporaron en el CPP de 1939. A posteriori, algunos de esos profesores en derecho -Velez Mariconde, Soler y Finzi- movilizaron ese capital simbólico para incidir en áreas externas al ámbito académico ${ }^{105}$.

En el campo político, el consenso que promovieron los especialistas se basó en la necesidad de cambiar un sistema inquisitorio por otro acusatorio que brindase mayores garantías al acusado, en mejorar la fase de instrucción y también en agilizar la tramitación y resolución de las causas judiciales. Al respecto, A. Sabattini en uno de sus mensajes a la Legislatura de Córdoba señalaba:

"La naturaleza secreta e inquisitiva de nuestro procedimiento criminal en pugna con los principios liberales que informan nuestro derecho público hace indispensable la transformación integral de la ley de enjuiciamiento criminal (...) mediante la supresión del principio de la prueba legal, abolición del secreto de sumario y articulación del proceso sobre las más amplias bases de la oralidad y publicidad de las causas"106.

Los conocimientos sobre investigación criminal que aportó Marcelo Finzi a la formación policial en Córdoba denotaron, al igual que lo ocurrido con Sebastián Soler y Alfredo Velez Mariconde, la movilización de saberes expertos desde el ámbito académico, en donde se establecieron los primeros intercambios y discusiones entre juristas locales y extranjeros, hacia el espacio institucional, específicamente en una repartición que se encontraba fuertemente cuestionada por partidos opositores al radicalismo, pero también por la sociedad en general, debido al estado público que tomó la desaparición de Marta Stutz.

De esta manera y como proponen Dezalay y Garth, encontramos la existencia de intercambios de saberes trasnacionales, en donde el accionar del gobierno se constituiría en una pieza importante a la hora de receptar los conocimientos en función de las tensiones entre las elites políticas locales. En ese marco, los contactos entablados por Amadeo Sabattini con los intelectuales partícipes de las innovaciones en la academia local habrían denotado el interés por parte de la gestión radical de promover transformaciones en la Justicia y en la administración policial por medio de la recepción de nuevos saberes en materia penal. En la policía esto significó implementar una serie de reformas en un primer momento para despolitizar la fuerza y ejercer un mayor control mediante del Poder Judicial y, luego, para dar respuestas a los cuestionamientos públicos que tenía la Policía de la Capital que también afectaban de manera directa a la gestión sabattinista y su defensa de la autonomía provincial ${ }^{107}$. 


\section{Conclusión} tuvieron una existencia anterior a lo sucedido en las cátedras de la UBA, aun con la presencia de los mismos intelectuales, como lo fue el caso de Luis Jiménez de Asúa. Como intentamos desarrollar a lo largo de este artículo, los cambios en Córdoba se gestaron por iniciativa de distintos profesores que integraron la Cátedra de Derecho Penal (UNC), quienes discutieron no solo los métodos de enseñanza de esta especialidad del Derecho, sino también la vinculación de los saberes académicos con la realidad social.

consolidación de los intercambios con expertos extranjeros se habría producido a partir de la creación del IDC, en donde los mismos se institucionalizaron, haciéndose también más frecuentes. Con respecto al rol de los expertos en la importación y exportación de saberes, consideramos que a las motivaciones de índole cultural se le sumó el interés de los juristas de ingresar en la administración estatal, teniendo en cuenta que los intelectuales mencionados desempeñaron sus tareas en el ámbito académico y en el institucional.

Específicamente el proyecto de CPP de 1939 integró una reforma en los tribunales a nivel regional, en donde las luchas entre las elites nacionales habrían encontrado, en ciertos modelos internacionales, los recursos para dirimir disputas locales ${ }^{108}$. Mientras los expertos habrían estado interesados en establecer alianzas políticas para materializar los cambios institucionalmente $\mathrm{y}$, a partir de allí, posiblemente ingresar a la burocracia estatal; las elites locales habrían negociado las características que tendría la recepción de saberes, en función de las luchas políticas mantenidas con otras elites. En tanto la burocracia policial cordobesa se vio afectada por los nuevos lineamientos penales que se estaban discutiendo en el mundo jurídico, muy presentes en la propuesta de modernización jurídica del sabattinismo.

El caso de la desaparición de Marta Stutz y su repercusión en la opinión pública de Córdoba constituyó una demanda externa que podría haber ejercido influencia para acelerar los cambios que se estaban produciendo en la repartición, planteando la necesidad de subsanar las negligencias cometidas por la policía en la etapa de instrucción, pero con menor impacto en el terreno legislativo. Este argumento se refuerza si consideramos que uno de los aspectos revisados del proyecto fue la creación de la Policía Judicial, que podría interpretarse como respuesta ante las irregularidades de la Policía de la Capital durante las investigaciones preliminares.

No obstante, y como intentamos desarrollar en este trabajo, los obstáculos en la materialización de las reformas procesales, respecto a la etapa de instrucción policial, no implicaron la ausencia de cambios en la repartición local. En este sentido, la capacitación, profesionalización y los reordenamientos del personal -en todas sus jerarquías- a partir de la creación de la Escuela de Policía se inscribiría, en primer lugar, en la dinámica propia de la burocracia policial; en segundo término, en el marco de demandas sociales en pos del mejoramiento de la institución en el esclarecimiento de los delitos y, en tercer lugar, en un contexto de disputas políticas-partidarias con la "politización" del caso Stutz y la amenaza de intervención del gobierno nacional en la provincia. Para cerrar, consideramos que articular estos procesos con las ideas, saberes y luchas en el espacio jurídico y en el político contribuiría a una explicación integral de las trasformaciones en las burocracias penales de Córdoba durante las décadas de 1930 y 1940.

Revista Historia y Justicia, 12 | 2019 


\section{Fuentes}

\section{Fuentes Inéditas}

Archivo Histórico de la Provincia de Córdoba, Córdoba, Argentina, Sub Fondo de Gobierno, Serie Policía, Tomo 32 (1938) y Tomo 33 (1939)

Archivo Histórico de la Provincia de Córdoba, Córdoba, Argentina, Sub Fondo de Gobierno, Serie Policía Capital, Tomo 36 (1940)

Archivo Histórico de la Provincia de Córdoba, Córdoba, Argentina, Sub Fondo de Gobierno, Serie Policía y Cárceles, Tomo 46 (1940)

\section{Fuentes Publicadas}

Alcalá-Zamora \& Castillo, Niceto, “Información: Necrología Alfredo Vélez Mariconde”, Boletín Mexicano de Derecho Comparado, Año V, №15, 1972, pp. 644-648. https:// revistas.juridicas.unam.mx/index.php/derecho-comparado/article/view/965/1225 [Consultado el 20 de septiembre de 2018]

Diario de sesiones de la Cámara de Diputados, Córdoba, sin pie de imprenta, 1939.

Diario de sesiones de la Cámara de Senadores, 2 Tomos, Córdoba, Talleres Gráficos Comercio y Tribunales, 1938.

Diario de Sesiones de la Cámara de Senadores, Córdoba, Talleres Gráficos Comercio y Tribunales, 1937.

Finzi, Marcelo, “Informe del secretario del Instituto", Boletín de la Facultad de Derecho y Ciencias Sociales, Año IV, Córdoba, 1942.

García Aramburu, Agustín, "El pensamiento de la reforma universitaria”, Liliana López Foresi, 30 de marzo de 2018. Disponible en http://lilianalopezforesi.com.ar/es/ [Consultado el 10 de septiembre de 2018]

83 Gómez, Eusebio \& Rodolfo Moreno, Proyecto de Código de Procedimiento Penal de la Provincia de Buenos Aires, Taller de Impresiones Oficiales, La Plata, 1935.

Ibarguren, Carlos, La historia que he vivido, Ediciones Digtio, Buenos Aires, 1969.

Lambert, Edouard, El Instituto de Derecho Comparado de Córdoba, Imprenta de la Universidad, Córdoba, Córdoba, 1939.

Núñez, Jorge, “Directivas del Instituto de Derecho Comparado de la Facultad”, Boletín de la Facultad de Derecho y Ciencias Sociales, Año IV, Córdoba, 1940.

7 Paz Casas, José Tristán, “Memoria escrita por el Jefe de Policía de la Capital al Ministro de Gobierno, Santiago H. Del Castillo”, en Memoria año 1937. Datos estadísticos e informes de las reparticiones de policía, Archivo Histórico de la Provincia de Córdoba, Córdoba, 1938. ttini, Amadeo, Mensajes a la Legislatura de la Provincia de Córdoba, del Gobernador Amadeo Sabattini, acerca del estado de la provincia, 1936-1940, Edición de la Secretaría Técnica Parlamentaria, Córdoba, 1992.

Soler, Sebastián, Derecho Penal Argentino, Tomo I, TEA, Buenos Aires, 1988. 

Provincia de Córdoba, Talleres Gráficos de la Cárcel Penitenciaria de Córdoba, Córdoba, 1941.

\section{Periódicos}

\section{BIBLIOGRAFÍA}

Barreneche, Osvaldo, "De brava a dura. La policía de la provincia de Buenos Aires durante la primera mitad del s. XX", Cuadernos de Antropología Social, Buenos Aires, nº32, 2010, p. 31-56. Barreneche, Osvaldo, "La reorganización de las policías en las provincias de Buenos Aires y Córdoba, 1936-1940", en Moreyra, Beatriz y Mallo, Silvia (Coord.), Procesos amplios, experiencia y construcción de las identidades sociales. Córdoba y Buenos Aires, siglos XVIII-XX, Publicación del Centro de Estudios Históricos "Prof. Carlos Segreti” y Universidad Nacional de Córdoba, Córdoba, 2007. Bernasconi Ramírez, Andrés, "El carácter científico de la dogmática jurídica”, Revista de Derecho, Vol. 20, n¹, 2007, p. 9-37.

Bourdieu, Pierre, "Elementos para una sociología del campo jurídico", en Bourdieu, Pierre \& Teubner, Gunther, La fuerza del derecho, Siglo del Hombre Editores, Bogotá, 2000.

Caimari, Lila \& Sozzo, Máximo (Comps.) Historia de la cuestión criminal en América Latina, Prohistoria Ediciones, Rosario, 2017.

Cesano, José Daniel, Contexto político, opinión pública y perfiles intelectuales en el proceso de codificación procesal penal de la provincia de Córdoba (1937-1939), Lerner Editora SRL, Córdoba, 2017.

Cesano, José Daniel, Viajeros y traductores: circulación de ideas en la formación de la cultura jurídico penal de Córdoba. Luis Jiménez de Asúa y Robert Goldschmidt, 1923-1952, Lerner Editora, Córdoba, 2015. Cesano, José Daniel, Marcello Finzi. La inclusión de un penalista exiliado en la cultura jurídica de Córdoba , Lerner Editora, Córdoba, 2014.

Cesano, José Daniel, “Luis Jimenez de Asua (1923-1930): viajes académicos, redes intelectuales y cultura jurídico-penal”, Revista de derecho penal y criminología, no2, 2013, p. 251-264.

Cesano, José Daniel, “Redes intelectuales y recepción en la cultura jurídico penal de Córdoba (1900-1950)", Rechtsgeschichte-Legal History, 2012, p. 156-169.

Cesano, José Daniel, “Sebastián Soler, la crítica al positivismo criminológico y el significado de su derecho penal argentino: saberes jurídicos y contextos intelectuales. Una aproximación desde la historia de las ideas", en Yanzi Ferreira, Ramón Pedro (Coord.) Cuadernos de historia, nº 20, Academia Nacional de Derecho y Ciencias Sociales de Córdoba, Córdoba, 2011, p. 89-113.

Cesano, José Daniel, “La creación del Instituto de Derecho Comparado de la Facultad de Derecho de la Universidad Nacional de Córdoba: Enrique Martínez Paz y un espacio de sociabilidad en la 
formación de la cultura jurídica de córdoba (1939-1947)", Acto de incorporación del académico correspondiente argentino Dr. José Daniel Cesano, Academia Nacional de Ciencias de Buenos Aires, Buenos Aires, 27 de abril de 2008.

Dezalay, Yves \& Garth, Bryant, Sociología de la internacionalización, Editorial Universitaria Villa María, Villa María, 2017.

Frederic, Sabina; Graciano, Osvaldo \& Soprano, Germán, “Profesión, Estado y política. Estudios sobre la formación académica y configuración profesional en la Argentina”, en Bohoslavsky, Ernesto \& Soprano, German (Coords.) El Estado argentino y las profesiones liberales, académicas y armadas, Prohistoria Ediciones, Rosario, 2010.

Garland, David, "Penalidad y Estado Penal”, en Delito y Sociedad, ํo43, 2015, p. 9-48.

Hathazy, Paul, "Punitivism with a human face: criminal justice reformers` international and regional strategies and penal-state making in Argentina, Chile and beyond", Kriminologisches Journal, Vol. 48, nº4, 2016, p. 294-309.

Hathazy, Paul, Democratizing Leviathan: Bureaucrats, experts and politics in the transformation of the Penal State in Argentina and Chile, Tesis de Doctorado en Sociología, University of California, Berkeley, 2013, p. 332.

Kalmanowiecki, Laura, Military power and policing in Argentina, 1900-1955, Tesis de Doctorado en Sociología, New School for Social Research, Nueva York, 1995, p. 388.

Langer, Máximo, "Revolución en el proceso penal latinoamericano: Difusión de ideas legales desde la periferia", Centro de Estudios de Justicia de las Américas, Santiago de Chile, 2007, p. 2-60. Disponible en: http://www.biblio.dpp.cl/biblio/DataBank/5312-2.pdf [Consultado el 10 de junio de 2018]

Lascano, Carlos Julio, "Breve semblanza de los juristas Marcelo Finzi y Corrado A. Finzi”, Acto de recepción de la "Colección Marcello u Corrado A. Finzi", Instituto de Ciencias Penales de la Academia Nacional de Derecho y Ciencias Sociales de Córdoba, Córdoba, 14 de marzo de 2018.

Levaggi, Abelardo, "Desarrollo del Derecho Procesal argentino en la primera mitad del siglo XX", Revista del Instituto de Historia del Derecho Ricardo Lavene, UBA, Facultad de Derecho y Ciencias Sociales, nํ2, Buenos Aires, 1979.

López Marsano, Charo \& Salas, Ernesto, ¡Viva Yrigoyen! ¡Viva la revolución! La lucha armada radical, 1930-1933, Editorial Biblos, Buenos Aires, 2017.

López Medina, Diego, "El nacimiento del derecho comparado moderno como espacio geográfico y como disciplina: instrucciones básicas para su comprensión y uso desde América Latina", International Law Revista Colombiana de Derecho Internacional, n²6, 2015, p. 117-159.

Luciano, Milena, "Las ideas penitenciarias en el campo jurídico cordobés. 1885 -1911", Anuario de la Escuela de Historia Virtual, Año 4, n4, 2013, p. 75-92. Disponible en : https://revistas.unc.edu.ar/ index.php/anuariohistoria/article/view/8388/9259 [Consultado el 10 de agosto de 2018]

Martínez, Josefina, “Las burocracias penales y su violencia naturalizada”, en Gayol, Sandra \& Kessler, Gabriel (Comps.) Violencias, delitos y justicias en la Argentina, Ediciones Manantial, Buenos Aires, 2002, p. 259-274.

Meichsner, Sylvia, "El campo político en la perspectiva teórica de Bourdieu", Revista de Ciencias Sociales de la Universidad Iberoamericana, Vol. II, n³, 2007, p. 1-22.

Morresi, Sergio \& Vommaro, Gabriel (Comps), Saber lo que se hace. Expertos y politica en Argentina, Prometeo/Universidad Nacional General Sarmiento, Buenos Aires, 2012. 
Osella, Desiré, "El Partido Demócrata de Córdoba en la coyuntura iniciada a partir del Golpe de Estado del 6 de septiembre de 1930", Anuario Digital, 2015, p. 180-210. Disponible en: http:// anuariodehistoria.unr.edu.ar/ojs/index.php/Anuario/article/view/176/200 [Consultado el $20 \mathrm{de}$ agosto de 2018]

Osella, Desiré, "El Partido Demócrata de Córdoba ante las elecciones de noviembre de 1931", Anuario del Instituto de Historia Argentina, $\mathrm{n}^{\circ} 14,2014$. Disponible en: https:// www.anuarioiha.fahce.unlp.edu.ar/article/view/IHAn14a05/pdf_28 [Consultado el 20 de agosto de 2018]

Palacios Muñoz, Daniel, "La reforma procesal penal en Chile: nuevos agentes, sus trayectorias y la reestructuración de un campo", Revista Política, Vol. 49, nº1, 2011, p. 43-70.

Philp, Marta, En nombre de Córdoba, Sabattinistas y peronistas: Estrategias políticas en la construcción del Estado, Ferreyra Editor, Córdoba, 1998.

Piñeiro, Elena, Los radicales antipersonalistas. Historia de una disidencia, Tesis de Doctorado en Historia, Universidad Torcuato Di Tella, Buenos Aires, 2007, p.366.

Plotkin, Mariano \& Zimmermann, Eduardo, "Introducción. Saberes de Estado en la Argentina, siglos XIX y XX”, en Plotkin, Mariano \& Zimmermann, Eduardo (Comps.) Los saberes del Estado, Edhasa, Buenos Aires, 2012.

Portelli, María B., “'Apasionado por ese movimiento científico': Cornelio Moyano Gacitúa y el estudio empírico de la delincuencia argentina del siglo XX”, Revista Historia y Justicia, n², 2017, p. 166-194. Disponible en: http://revista.historiayjusticia.org/wp-content/uploads/2017/05/hRHyJ-8-Varia-PORTELLI-ESTILADO-FINAL1.pdf [Consultado el 5 de abril de 2019]

Potash, Robert, El ejército y la política en la Argentina. De Yrigoyen a Perón, Editorial Sudamericana, Buenos Aires, 1981.

Rock, David, La Argentina Autoritaria. Los nacionalistas, su historia y su influencia en la vida pública, Ariel, Buenos Aires, 1993.

Ramos Mejía, Enrique, "La teoría del delito desde Von Liszt y Beling a hoy”, Idearium, Mendoza, n 4-5, noviembre de 1979, p.19-21.

Schiavoni, Martin, Positivismo criminológico, dogmática jurídica penal y enseñanza universitaria (UNC; ca. 1940-ca. 1970) Un estudio acerca de un cambio de paradigma en los saberes penales, Tesis de Maestría en Criminología, Facultad de Derecho, Universidad Nacional del Litoral, Santa Fe, 2017.

Tcach, Cesar, “Un parto frustrado: la intervención federal a Córdoba (1936-37)”, en Macor, Darío y Piazzesi, Susana (Eds.), Territorios de la política argentina. Córdoba y Santa Fe, 1930-1945, Ed. Universidad Nacional del Litoral, Santa Fe, 2009, p. 61-86.

Tcach, Cesar, "Un radicalismo exitoso en la Argentina de los treinta. El caso del sabattinismo cordobés”, Boletín Americanista, Barcelona, nํ57, 2007, p. 133-156.

Tcach, Cesar, La nación y la isla, Fondo de Cultura Económica, Buenos Aires, 1999.

Vasallo, Jaqueline, “De reos a imputados. Las nuevas garantías procesales en la Córdoba sabattinista”, en Macor, Dario \& Piazzesi, Susana (Eds.), Territorios de la política argentina, Ed. Universidad Nacional del Litoral, Santa Fe, 2009, p. 113-134.

Vecchioli, Virginia, "Profesionales del derecho, activismo jurídico y creación de nuevos derechos. Hacia una mirada comprensiva del derecho desde las ciencias sociales", Revista Política, Santiago, Vol. 49, nำ1, 2011, p. 5-18. 


\section{NOTAS}

1. Potash, Robert, El ejército y la política en la Argentina. De Yrigoyen a Perón, Editorial Sudamericana, Buenos Aires, 1981, p. 69.

2. Entre los grupos nacionalistas existentes en los años treinta se encontraban los siguientes: Liga Republicana, Legión Cívica, Legión de Mayo, Restauración de Milicias Cívicas y Guardia Argentina. Según lo planteado por D. Rock, el nacionalismo se caracterizó por su desarticulación en facciones que compartían la finalidad de evitar el resurgimiento del yrigoyenismo, homologándolo en ocasiones con el comunismo. Rock, David, La Argentina autoritaria. Los nacionalistas, su historia y su influencia en la vida pública, Ariel, Buenos Aires, 1993, p. 109.

3. Kalmanowiecki, Laura, Military power and policing in Argentina, 1900-1955, Tesis de doctorado en sociología, New School for Social Research, Nueva York, 1995, p. 175.

4. Caimari, Lila \& Sozzo, Máximo (Comps.), Historia de la cuestión criminal en América Latina, Prohistoria Ediciones, Rosario, 2017, p. 13.

5. Entre los primeros abordajes sobre la historia de la fuerza, se encuentra Retamoza, Víctor, B reve historia de la Policía de Córdoba, 1983. Desde una mirada institucional, el autor relata su organización y profesionalización desde 1870 hasta mediados del siglo XX.

6. Barreneche, Osvaldo, "La reorganización de las policías en las provincias de Buenos Aires y Córdoba, 1936-1940”, en Moreyra, Beatriz \& Mallo, Silvia (Coords.), Procesos amplios, experiencia y construcción de las identidades sociales. Córdoba y Buenos Aires, siglos XVIII-XX, Publicación del Centro de Estudios Históricos “Prof. Carlos Segreti” y Universidad Nacional de Córdoba, Córdoba, 2007.

7. Levaggi, Abelardo, "Desarrollo del derecho procesal argentino en la primera mitad del siglo XX”, Revista del Instituto de Historia del Derecho Ricardo Lavene, Buenos Aires, ㄲ25, 1979.

8. Vasallo, Jaqueline, "De reos a imputados. Las nuevas garantías procesales en la Córdoba sabattinista", en Macor, Dario \& Piazzesi, Susana (Eds.), Territorios de la política argentina, Ed. Universidad Nacional del Litoral, Santa Fe, 2009, p.113-134.

9. Garland, David, "Penalidad y Estado Penal", Delito y Sociedad, ํo43, 2015, pp. 31-32.

10. En una nota titulada "El rapto de la niña Martha Stuz [sic.]", la reconocida revista Caras y Caretas, de origen uruguayo y publicada en la ciudad de Buenos Aires desde 1898, señalaba la "indignación y estupor" que generaba en el público la desaparición de la niña y la ausencia de información sobre su paradero, sugiriendo que una de las hipótesis que se estaban manejando en ese momento le atribuía el hecho a "la mafia", sin brindar mayores datos al respecto. Véase, "El rapto de la niña Martha Stuz", Caras y Caretas, n²096, 3 de diciembre de 1938.

11. López Medina, Diego, "El nacimiento del derecho comparado moderno como espacio geográfico y como disciplina: instrucciones básicas para su comprensión y uso desde América Latina”, International Law Revista Colombiana de Derecho Internacional, №26, 2015, p. 138-140.

12. Cesano, José Daniel, “Luis Jiménez de Asúa (1923 - 1930): viajes académicos, redes intelectuales y cultura jurídico - penal”, Revista de derecho penal y criminología, №2, 2013, p. 255-257.

13. Schiavoni, Martin, Positivismo criminológico, dogmática jurídica penal y enseñanza universitaria (UNC; ca. $1940 \sim$ ca. 1970) Un estudio acerca de un cambio de paradigma en los saberes penales, Tesis de Maestría en Criminología, Facultad de Derecho, Universidad Nacional del Litoral, Santa Fe, 2017, p. 12-16.

14. Cesano, J. D., "Luis Jiménez de Asúa”, Op. Cit., p. 8.

15. La orientación de la cátedra de Derecho Penal de la Facultad de Derecho de la UNC articulaba contenidos de la Scuola Positiva y preceptos de la Escuela Penal Clásica. Al respecto, véase Cesano, José D., "Redes intelectuales y recepción en la cultura jurídico penal de Córdoba (1900-1950)", Rechtsgeschichte-Legal History, 2012, p. 157. 
16. Luciano, Milena, "Las ideas penitenciarias en el campo jurídico cordobés. 1885 -1911”, Anuario de la Escuela de Historia Virtual, Año 4, n4 2013, p. 81. Disponible en: https://revistas.unc.edu.ar/ index.php/anuariohistoria/article/view/8388/9259 [Consultado el 10 de agosto de 2018]

17. Portelli, María B., “'Apasionado por ese movimiento científico’: Cornelio Moyano Gacitúa y el estudio empírico de la delincuencia argentina del siglo XX", Revista Historia y Justicia, n 8, 2017, p. 178. Disponible en: http://revista.historiayjusticia.org/wp-content/uploads/2017/05/h-RHyJ-8Varia-PORTELLI-ESTILADO-FINAL1.pdf [Consultado el 5 de abril de 2019]

18. Bernasconi Ramirez, Andrés, "El carácter científico de la dogmática jurídica", Revista de Derecho, Vol. 20, n¹, 2007, p. 15.

19. Formulado por el jurista húngaro Franz von Liszt.

20. Ramos Mejía, Enrique, "La teoría del delito desde Von Liszt y Beling a hoy", Idearium, Mendoza, $n^{\circ}$ 4-5, noviembre de 1979, p. 19-21.

21. Enrique Martínez Paz fue director del Instituto de Derecho Civil Comparado entre 1925 y 1929.

22. El American Bar Association (Colegio de Abogados de Estados Unidos) fue creado en 1878, mientras que el American Law Institute (Instituto de Derecho Americano) data de 1923. Entre sus principales finalidades se encontraban atenuar el regionalismo jurídico del Common Law, buscando uniformidad en el derecho norteamericano.

23. Lambert, Edouard, El Instituto de Derecho Comparado de Córdoba, Imprenta de la Universidad, Córdoba, 1939.

24. Cesano, José Daniel, "La creación del Instituto de Derecho Comparado de la Facultad de Derecho de la Universidad Nacional de Córdoba: Enrique Martínez Paz y un espacio de sociabilidad en la formación de la cultura jurídica de córdoba (1939-1947)". Acto de incorporación del académico correspondiente argentino Dr. José Daniel Cesano, Academia Nacional de Ciencias de Buenos Aires, Buenos Aires, 27 de abril de 2008, p. 16.

25. Cesano, José Daniel, Viajeros y traductores: circulación de ideas en la formación de la cultura jurídico penal de Córdoba. Luis Jiménez de Asúa y Robert Goldschmidt, 1923-1952, Lerner Editora, Córdoba, 2015, p. 119-121.

26. Lascano, Carlos Julio, "Breve semblanza de los juristas Marcelo Finzi y Corrado A. Finzi”, Acto de recepción de la "Colección Marcello y Corrado A. Finzi, Instituto de Ciencias Penales de la Academia Nacional de Derecho y Ciencias Sociales de Córdoba, Córdoba, 14 de marzo de 2018.

27. Cesano, J. D., Viajeros y traductores, Op. Cit., p. 60.

28. Finzi, Marcelo, "Informe del secretario del Instituto", Boletín de la Facultad de Derecho y Ciencias Sociales, Córdoba, Año IV, 1942.

29. García Aramburu, Agustín, "El pensamiento de la reforma universitaria". Liliana López Foresi, 30 de marzo de 2018. Disponible en: http://lilianalopezforesi.com.ar/es/ [Consultado el 10 de septiembre de 2018]

30. Entre las principales obras de Sebastián Soler se encuentran "La intervención del Estado en la peligrosidad predelictual" (1926) y "Parte general del Derecho Penal argentino", base metodológica de la explicación del delito como modelo de análisis dogmático. Al respecto, véase Cesano, José Daniel, “Redes intelectuales y recepción”, Op. Cit., p. 8 - 12.

31. Cesano, José Daniel, Contexto político, opinión pública y perfiles intelectuales en el proceso de codificación procesal penal de la provincia de Córdoba (1937-1939), Lerner Editora, Córdoba, 2017, p. 79.

32. Cesano, J. D., Contexto político, opinión pública, Op. Cit., p. 81.

33. Alcalá-Zamora \& Castillo, Niceto, "Información: Necrología Alfredo Vélez Mariconde”, Boletín Mexicano de Derecho Comparado, Año V, no15, 1972, p. 644-648.

34. Hathazy, Paul, Democratizing Leviathan: Bureaucrats, experts and politics in the transformation of the Penal State in Argentina and Chile, Tesis de Doctorado en Sociología, University of California, Berkeley, 2013, p.113.

35. Cesano, J. D., Viajeros y traductores, Op. Cit., p. 24. 
36. Morresi, Sergio \& Vommaro, Gabriel (Comps.), Saber lo que se hace. Expertos y política en Argentina, Prometeo / Universidad Nacional General Sarmiento, Buenos Aires, 2012, p. 31.

37. Ibíd., p. 14.

38. Langer, Máximo, "Revolución en el proceso penal latinoamericano: Difusión de ideas legales desde la periferia", Centro de Estudios de Justicia de las Américas, Santiago de Chile, 2007, p. 20. Disponible en: http://www.biblio.dpp.cl/biblio/DataBank/5312-2.pdf [Consultado el 10 de junio de 2018]

39. Langer, M., "Revolución en el proceso penal latinoamericano", Op. Cit. p. 21.

40. Bourdieu, Pierre, "Elementos para una sociología del campo jurídico", en Bourdieu, Pierre \& Teubner, Gunther, La fuerza del derecho, Siglo del Hombre Editores, Bogotá, 2000, p. 159-162.

41. Hathazy, P. Democratizing Leviathan, Op. Cit. p. 111.

42. Dezalay, Yves \& Garth, Bryant, Sociología de la internacionalización, Editorial Universitaria Villa María, Villa María, 2017, p. 236.

43. Dezalay, Y. \& Garth, Sociología, Op. Cit., p. 231.

44. Kalmanowiecki, L., Militarypower and policing, Op. Cit., p. 85-86.

45. Ibid., p. 171-172.

46. Tcach, Cesar, "Un radicalismo exitoso en la Argentina de los treinta. El caso del sabattinismo cordobés”, Boletín Americanista, nํ5, Barcelona, 2007, p. 134.

47. López Marsano, Charo \& Salas, Ernesto, ¡Viva Yrigoyen! ¡Viva la revolución! La lucha armada radical, 1930-1933, Editorial Biblos, Buenos Aires, 2017, p. 83.

48. Ibíd., p. 63.

49. Tcach, Cesar, La nación y la isla, Fondo de Cultura Económica, Buenos Aires, 1999, p.29.

50. Ibarguren, Carlos, La historia que he vivido, Ediciones Digtio, Buenos Aires, 1969, p. 552.

51. Desde su fundación en 1913 hasta 1928, los demócratas se constituyeron como partido de gobierno, con breves alternancias del radicalismo. Al respecto, véase Osella, Desiré, "El Partido Demócrata de Córdoba ante las elecciones de noviembre de 1931", Anuario del Instituto de Historia Argentina, $\mathrm{n}^{\circ}$ 14, 2014, p. 2. Disponible en: https://www.anuarioiha.fahce.unlp.edu.ar/article/ view/IHAn14a05/pdf_28 [Consultado el 20 de agosto de 2018]

52. Osella, Desiré, "El Partido Demócrata de Córdoba en la coyuntura iniciada a partir del Golpe de Estado del 6 de septiembre de 1930", Anuario Digital, 2015, p. 186. Disponible en: http:// anuariodehistoria.unr.edu.ar/ojs/index.php/Anuario/article/view/176/200 [Consultado el 20 de agosto de 2018]

53. Kalmanowiecki, L., Military power and policing, Op. Cit., p. 192.

54. López Marsano, C. \& Salas, E. ¡Viva Yrigoyen!, Op. Cit., p. 190.

55. Kalmanowiecki, L., Military power and policing, Op. Cit., p. 174 - 175.

56. Sabattini, Amadeo, Mensajes a la Legislatura de la Provincia de Córdoba, del gobernador Amadeo Sabattini, acerca del estado de la provincia, 1936-1940, Edición de la Secretaría Técnica Parlamentaria, Córdoba, 1992, p. 12.

57. Tcach, Cesar, “Un parto frustrado: la intervención federal a Córdoba (1936-37)”, en Macor, Darío y Piazzesi, Susana (eds.), Territorios de la política argentina. Córdoba y Santa Fe 1930-1945, Ed. Universidad Nacional del Litoral, Santa Fe, 2009, p. 67.

58. Philp, Marta, En nombre de Córdoba, Sabattinistas y peronistas: Estrategias políticas en la construcción del Estado, Ferreyra Editor, Córdoba, 1998, p. 80.

59. Tcach, C. La Nación y la Isla, Op. Cit., p. 39.

60. Vasallo, J. “De reos a imputados”, Op. Cit., p. 119.

61. Cesano, J. D. Contexto político, opinión pública, Op. Cit., p. 65.

62. Ibíd., p. 51-52.

63. Ibíd., p. 56.

64. A partir del caso norteamericano, D. Garland propone que las políticas penales podrían explicarse considerando las decisiones de las elites dirigentes y en menor medida por las 
presiones sociales, por lo cual su accionar se encontraría delimitado por el grado de apertura que posea la estructura del Estado respecto del contexto social en el que se inserta. En efecto, el autor distingue cinco dimensiones del Estado Penal: autonomía estatal, autonomía interna, control del poder de castigar, modalidades de poder penal y capacidades y recursos de poder. Véase Garland, D. "Penalidad y Estado Penal", Op. Cit., p. 31-37.

65. Garland, D. "Penalidad y Estado Penal”, Op. Cit., p. 31-32.

66. Cesano, J. D. Contexto político, opinión pública, Op. Cit., p. 108-109.

67. La Voz del Interior, "Desapareció de su casa una niña de 9 años”, 20 de diciembre de 1938.

68. La Voz del Interior, "Colabore lector en la pesquisa", (23 de noviembre de 1938.

69. Vasallo, J. "De reos a imputados", Op. Cit., p. 121.

70. La Voz del Interior, "Hoy entrara a actuar directamente el comisario Finochietto", 1 de diciembre de 1938.

71. Asumir la defensa de Antonio Suarez Zavala le reportó al reconocido dirigente reformista Deodoro Roca importantes repudios por parte de algunos sectores de la sociedad cordobesa.

72. La Voz del Interior, "Ha habido agentes provocadores de las protestas populares", 20 de diciembre de 1938.

73. Vasallo, J. “De reos a imputados", Op. Cit., p. 121-122.

74. La Voz del Interior, "La investigación ha carecido de Completa Unidad", 19 de diciembre de 1938.

75. Archivo Histórico de la Provincia de Córdoba (en adelante, AHPC) 1938, Serie Policía (Policía), Tomo (t.) 32, f. 384.

76. AHPC 1938, Policía, t. 32, f. 387.

77. AHPC 1938, Policía, t. 32, f. 390.

78. Barreneche, Osvaldo (2010) "De brava a dura. La policía de la provincia de Buenos Aires durante la primera mitad del S.XX", Cuadernos de Antropología Social, Buenos Aires, no32, 2010, p. 37.

79. La Voz del Interior, "La diputación demócrata interpeló anoche al ministro de Gobierno por la gestión policial”, 27 de diciembre de 1938.

80. La Voz del Interior, "En sesión especial tratará hoy la Cámara de Diputados una cuestión de privilegios", 31 de diciembre de 1938.

81. La división del radicalismo en "antipersonalistas" e "yrigoyenistas" data de la asunción de Hipólito Yrigoyen a la primera presidencia, no obstante, se institucionalizó en un partido político en las elecciones nacionales de 1928.Al respecto, véase Piñeiro, Elena, Los radicales antipersonalistas. Historia de una disidencia, Tesis de Doctorado en Historia, Universidad Torcuato di Tella, Buenos Aires, 2007, p. 6.

82. AHPC, 1938, Policía, t. 32, f. 391.

83. Cesano, J. D., Contexto político, opinión pública, Op. Cit., p. 96.

84. Hathazy, P. Democratizing Leviathan, Op. Cit. p. 111.

85. Langer, M., "Revolución en el proceso penal latinoamericano", Op. Cit. p.6.

86. Vélez Mariconde, Alfredo \& Soler, Sebastián, Proyecto de Código de Procedimiento Penal de la Provincia de Córdoba, Talleres Gráficos de la Cárcel Penitenciaria de Córdoba, Córdoba, 1941, p. 81.

87. Ibíd., p. 41.

88. Diario de Sesiones Cámara de Diputados, $34^{\mathrm{a}}$ reunión, $25^{\mathrm{a}}$ sesión ordinaria, 22 de agosto de 1939, p. 905.

89. Ibíd., p. 925.

90. Martínez, Josefina, "Las burocracias penales y su violencia naturalizada”, en Gayol, Sandra \& Kessler, Gabriel (Comps.), Violencias, delitos y justicias en la Argentina, Ediciones Manantial, Buenos Aires, 2002, p. 261-262.

91. Vélez Mariconde, A. \& Soler, S., Proyecto de Código, Op. Cit., p. 56-57.

92. Cesano, J. D., Contexto político, opinión pública, Op. Cit., p. 122-126. 
93. Vélez Mariconde, A. \& Soler, S. Proyecto de Código, Op. Cit., p. 114.

94. Los autores consultaron, a un conjunto de magistrados y a los representantes de los colegios de abogados de la provincia, alternativas prácticas para la creación de juzgados abocados a la instrucción previa al juicio, atendiendo a los recursos que demandaba, dada la extensión de la provincia de Buenos Aires. Sobre el particular, véase Gómez, Eusebio \& Moreno, Rodolfo, Proyecto de Código de Procedimiento Penal de la Provincia de Buenos Aires, Taller de Impresiones Oficiales, La Plata, 1935, p. 51-110.

95. Barreneche, O., “La reorganización de las policías”, Op. Cit., p. 14.

96. Durante la gestión sabattinista, la Policía de la Capital contó con tres jefes: José Tristán Paz Casas (1936-1938), Argentino Autcher (1938), Víctor José de la Peña (1938-1943). Véase Barreneche, O., "La reorganización de las policías”, Op. Cit., p. 13.

97. Paz Casas, José Tristán, "Memoria escrita por el Jefe de Policía de la Capital al Ministro de Gobierno, Santiago H. Del Castillo", en Memoria año 1937. Datos estadísticos e informes de las reparticiones de policía, Archivo Histórico de la Provincia de Córdoba, Córdoba, 1938, p.21.

98. Ibíd., p. 22.

99. El antecedente más próximo fue la Escuela de Cadetes y Vigilantes de la ciudad de Córdoba (1913), promovida por la Escuela de Policía de la Capital Federal, pero con una existencia muy breve. La nueva institución funcionó hasta 1943, debido a un nuevo Golpe de Estado. Luego se volvió a crear otra Escuela de Policía en 1952, bajo el gobierno peronista. Sobre las primeras escuelas de policía, véase Barreneche, O., "La reorganización de las policías”, Op. Cit., p.18.

100. El primer director de la Escuela de Policía de la Provincia de Córdoba fue Salustiano Álvarez. 101. AHPC, 1939, Policía, t.33, f. 90.

102. AHPC, 1939, Policía, t. 33, f. 91.

103. AHPC, 1940, Policía, t. 46, fs. 291, 292 y 312.

104. "Programa del curso de conferencias relativas a la policía científica que será desarrollado por el Profesor Marcelo Finzi en la Escuela de Policía”, AHPC, 1940, Policía, t. 36, f. 311.

105. Morresi, S. \& Vommaro, S., Saber lo que se hace, Op. Cit., p. 18.

106. Sabattini, Amadeo, Mensajes a la Legislatura de la Provincia de Córdoba, del Gobernador Amadeo Sabattini, acerca del estado de la provincia, 1936-1940, Edición de la Secretaría Técnica Parlamentaria, Córdoba, 1992, p.16.

107. Un caso similar al de Córdoba, que ilumina algunos aspectos acerca de las modalidades de articulación entre academia y espacio político, fue lo sucedido en Chile durante la transición democrática posterior a la dictadura de Augusto Pinochet, a finales de la década del ochenta y principios de 1990. Allí los especialistas promovieron un proyecto de reforma en el campo jurídico, en donde se propusieron una serie de cambios respecto del derecho procesal tradicional de impronta inquisitorial y la creación de seminarios y conferencias en donde se habría "fabricado" el problema y las posibles soluciones. El contexto político favorable permitió establecer alianzas con determinados sectores políticos, en particular con la ministra de Justicia Soledad Alvear, quién además de mejorar su posición dentro de la Concertación, capitalizó un logro para la gestión en el área judicial. Sobre este tema, véase Palacios Muñoz, Daniel, "La reforma procesal penal en Chile: nuevos agentes, sus trayectorias y la reestructuración de un campo", Revista Política, Vol. 49, nº1, 2011, p. 52-61.

108. Hathazy, Paul, "Punitivism with a human face: criminal justice reformers' international and regional strategies and penal-state making in Argentina, Chile and beyond", Kriminologisches Journal, Vol. 48, nº4, 2016, p. 307-308. 


\section{RESÚMENES}

En este trabajo abordamos el proceso de reforma del Código de Procedimiento Penal de la provincia de Córdoba, Argentina, proyectado por los juristas argentinos Alfredo Vélez Mariconde y Sebastián Soler, en 1939. Proponemos relacionar la formación de redes trasnacionales de especialistas -a través de la Facultad de Derecho de la Universidad Nacional de Córdoba y del Instituto de Derecho Comparado-, con el contexto político y las luchas político partidarias que se estaban desarrollando a nivel nacional y provincial, antes y durante la gestión del gobernador de Córdoba Amadeo Sabattini (1936-1940), que involucraron la participación de las burocracias penales provinciales, especialmente de la justicia y de la policía.

This paper deals with the reform process of the Criminal Proceeding Code for the Cordoba province, in Argentina, that was projected by the Argentinian jurists Alfredo Vélez Mariconde and Sebastián Soler in 1939. The article establishes the connection between the formation of transnational networks of specialists through the Faculty of Law at the Cordoba National University, and the Comparative Law Institute, on one hand, with the political context and the struggles developped at national and provincial levels, on the other hand, before and during Amadeo Sabattini's administration (1936 - 1940) as governor of Cordoba. This involved the participation of the provincial criminal bureaucracies, especially the Justice and the Police.

Cet article concerne la réforme du Code de Procédure Pénale de la province de Cordoba, en Argentine, projetée par les juristes argentins Alfredo Vélez Mariconde et Sebastián Soler en 1939. Il établit qu'il existait un lien entre la formation de réseaux internationaux de spécialistes à travers la Faculté de Droit de l'Université Nationale de Cordoba et l'Institut de Droit Comparé, d'un côté, et le contexte politique et les luttes aux niveaux provincial et national, d'un autre côté, avant et pendant l'administration du gouverneur Amadeo Sabattini (1936-1940). Cela impliquait la participation des bureaucraties criminelles de la province, notamment la Police et la Justice.

\section{ÍNDICE}

Palabras claves: burocracias penales, Código procesal penal, sabattinismo, Argentina, década de 1930

Mots-clés: bureaucratie pénale, années 30, code de procédure pénale, sabattinisme, Argentine Keywords: penal bureaucracies, criminal procedure code, sabattinism, Argentina, 1930's

\section{AUTOR}

\section{MILENA LUCIANO}

Licenciada en Historia, Universidad Nacional de Córdoba. Doctoranda en Historia, Universidad Nacional de La Plata. Becaria Doctoral CONICET (2017-2022), integrante del programa "Estados, poderes y control social: perspectivas histórico-comparativas", Centro de Investigaciones y 
Estudios sobre Cultura y Sociedad, CIECS, CONICET-Córdoba, coordinado por el Dr. Paul Hathazy. Correo electrónico: mileluciano31[at]gmail.com 